\title{
Socio-economic factors as causes and remedies for conflict of the San community in Platfontein
}

\begin{abstract}
$H G$ BEYENE ${ }^{1}$
Abstract

The study examines the role of socio-economic factors in conflict in the San community of Platfontein. This article's analysis is based on the primary data collected from individual interviews and focused group discussions conducted in 2013 and 2014. It reveals that socioeconomic factors are both the cause of the conflict and serve as remedies for the conflict. The causes date back to the historical displacement and dispossession of land the community faced. The San community is highly dependent on the limited income of a few veterans while the vast majority is unemployed. The lack of skills and limited command of the dominant language in the community makes them less able to compete for jobs. The community's economic hardships are increased by the dependency syndrome shown by the adults, who tend towards job-seeking rather than job creation and self-reliance. The economic hardship has become one formidable cause of conflict in the community. A concerted effort is needed to change the attitude of the community so that it becomes entrepreneurial and independent.

One factor that erodes unity within the San community is that the leadership does not work closely with the people - a situation that increases the likelihood of conflict. The efforts undertaken to empower the San community and lift them out of poverty are very limited. The conflict between !Xun and Khwe is attributed to the divisive political rule adopted during the apartheid regime in South Africa. Comparative economic asymmetries between !Xun and Khwe are also causes of conflict. Furthermore, the widening of social distance, along with competition for jobs and housing, increases the tensions and divisions between the !Xun and Khwe communities. The cause of conflict between the San community and other communities is also associated with unemployment and unfair treatment. Socio-economic factors are valuable ingredients in the process of conflict resolution and healing the emotional problems of the conflicting parties.
\end{abstract}

Keywords: conflict, emotional healing, Platfontein, resolution process, San, community, socioeconomic factors, !Xun, Khwe

\section{Introduction}

The issue of conflict resolution is as old as the history of mankind. It has been defined in different ways, based on different perspectives by various scholars.

Conflict is a state of discord caused by the actual or perceived diversity in needs, values and interests. Conflict takes place when two or more parties find their interests incompatible and express hostile attitudes towards each other, or take action which damages the ability of the other parties to pursue their interest (Mustafa 2013). ${ }^{2}$

1 Post-Doctoral Fellow at the Institute for Dispute Resolution, University of South Africa (Unisa).

2 The definition is given as shown by Mustafa (2013) citing the works of Fathali \& Rom (2010) and Sandole \& Van der Merwe (1995).

Td The Journal for Transdisciplinary Research in Southern Africa, 10(4) December 2014,

Special edition: San dispute resolution, pp. 99-119. 
It is one of the most frequently discussed and debated issues, as the literature indicates. Before highlighting the multitude of arguments, here is a brief historical background of the San community that is the focus of this study.

The San community has been deprived of possessing natural resources and has been exposed to displacement for more than 300 years. After the victory of National Party in the 1948 election, the San community was categorised as "coloured" and lived in poverty in the remote areas of Northern Cape. The San community has been exposed to harsh living conditions and an extremely marginalised status for about four decades. The !Xun and Khwe, who were on the side of the Portuguese in Angola and Namibia, fought against apartheid and later fled to South Africa along with South African Defence Force (SADF) (Robins 2001).

The process of relocation from Namibia was carried out in 1990, when 500 veterans of the SADF's "Bushman battalions" along with their 3500 dependents relocated to Schmidtsdrift. The SADF decided on this relocation to protect the Bushman battalion soldiers from the likelihood of retribution by the new Swapo government in Namibia. The SADF believed that retribution was inevitable, as the Bushman battalions had been against Swapo in the independence struggle in the 1980s. However, contrary to the expectations of the SADF, Swapo took no retaliatory action against the members of the Bushmen battalions who decided to remain in Namibia. Then the SADF facilitated the granting of South African citizenship to 4000 relocated people at Schmidtsdrift. In the post-apartheid era 360 San soldiers were integrated into the South African National Defence Force (SANDF) (Robins 2001).

Mahongo (2014) explains that from 1990 the San tribe arrived in South Africa with the help of the SADF, which provided it with food for few months. There were 350 people from the San community employed as soldiers in the SADF, which later increased to 600. These 600 soldiers were financially responsible for the whole community at that time. Later people were made to work on farms, which helped generate more income for the community's survival.

Of the two peoples of the San community that moved to South Africa, the Khwe come from Botswana and the !Xun are mainly from Angola (Swart 2014). When they arrived in South Africa they lived in tents at the military camp based in Schmidtsdrift, close to Kimberley, for about 10 years until they were eventually relocated to a permanent settlement area where housing and other facilities were provided (Robins 2001).

The dislocation of the San community (the !Xun, Khwe and $¥$ Khomani), and their eviction to relatively unproductive and remote areas, ended in South Africa in 1999 when they were placed in two principal land settlements. The Khomani San were entitled to their own land: the other San communities, the !Xun and Khwe, which settled in Platfontein, are entitled to own farmland closer to Kimberley (Robins 2001). In June 1999, the African National Congress granted land to 4500 !Xun and Khwe San people. Currently, the total population of the San community at Platfontein is 7 000. Of these about 4500 are !Xun and the rest are Khwe (Beyene 2014c).

This settlement has changed their way of life from nomadic to sedentary. This new secure sedentary lifestyle is presumed to offer greater opportunities to transform their lives, and is viable if supported by development schemes that allow the community to settle sustainably (Robins 2001).

The San people were considered authentic Bushmen who kept their original identity for decades. They presented themselves to outsiders as primordial pure Bushmen by conforming 
to the myths about and attitudes to Bushmen commonly held in the West. This process continued until after the end of apartheid. The peculiarities of the San have been an issue that attracted the attention of journalists, photographers and film-makers who created global awareness of the community. The San do not benefit from such activities, which focus on the distinctive features of the group (Robins 2001).

After 1994, the San people who had been soldiers came into conflict with the new South African Defence Force, especially over the type of discipline it followed. As a result many of the San soldiers opted to take early retirement; however, one of the problems these soldiers then faced was a language or communication problem. The San soldiers' medium of communication used to be Afrikaans, but others in the army in the new dispensation prefer to communicate in English. This communication problem also contributed to military personnel from the San community leaving the army (Beyene 2014b).

Collier (2006) points out that the communities in Platfontein are now, post-conflict, exposed to higher risks that polarise grievances even more than before.

\section{Methodology}

The study is principally based on fieldwork that involved data collection through interviews with selected respondents from the San settlement areas of Platfontein, with a focus on !Xun and Khwe San. A total of 250 interviews and focused group discussions were held in 2013 and 2014. This study has made use of the data collected in both the individual interviews and focused group discussions. To strengthen the quality of the study, data was also collected from selected key informants at a retreat workshop in 2014. In this workshop, the study also used individual as well as group discussion approaches to obtain detailed facts about the socioeconomic situations and dispute resolution practices of the specified San communities. Furthermore, relevant literature about the San community was reviewed to substantiate the data and analysis of the study. The retreat workshop organised in Pretoria also opened up an opportunity for informal communication that further enhanced the researchers' understanding of the dynamics of the San community.

\section{Rationale of the study}

The study is intended to examine the socioeconomic factors that serve as a cause as well as a solution for the conflicts that arise in the San community. This will help to explain the role of socioeconomic factors in the conflict and pacification processes. The study examines the role of socioeconomic factors in conflict between the communities of the San; between San and other communities; and during the process of conflict resolution. Further, it addresses how socioeconomic factors should be treated in the community's social setting in a way that enhances peaceful living patterns.

\section{Literature review}

Violence can be determined by economic or non-economic factors or a blend of both (Krueger \& Maleckova 2003). With regard to the conflict-poverty nexus there are two schools of thought. While the first argues that poverty gives rise to conflict, the other school 
argues the reverse. Various scholars use different terminologies in presenting their arguments about the relationship between poverty and conflict. These include indirect relationship, twoway association and complex relationship, or a bifurcated type (Ikejiaku 2012).

The relationship between conflict and poverty is widely observed, as they are closely interwoven. Both of them explain the suffering of human beings. Poverty can result in conflict when complaints and grievances are not resolved; poverty-stricken people may revolt or challenge the administration in other ways. Furthermore, deterioration in economic conditions can lead to the eruption of violence (Ikejiaku 2012).

The Centre for the Study of Violence and Reconciliation (CSVR) (2009) examined the violence rate and its causes. It stated that violence in South Africa is caused by high levels of inequality and poverty, unemployment, marginalisation, and uneven treatment of South Africans and others by state institutions performance. Luckham, Ismail, Muggah and White (2001:1) state that "war and poverty are in a dynamic and mutually reinforcing relationship. Not only has armed conflict been a major determinant of poverty in sub-Saharan Africa, poverty has amplified conflict's impact and made civilians more vulnerable. And in turn poverty and inequality remain among the major sources of conflict".

One of the fundamental factors that play a role in preventing civil strife is the implementation of both economic and political reforms simultaneously in a way that attempts to distribute both costs and benefits to the communities (Brinkman 2001).

In South Africa, although there were many other factors the apartheid regime is blamed for, the cause of conflict is stated thus: "... the immediate cause of the conflict could be linked to the high rate of poverty and unemployment arising from politicisation of every bit of life in the homeland" (Irobi 2005:4).

The impact of poverty on conflict is further supported by Archbishop Tutu's warning to South Africa: "If the disadvantaged, the poor, the homeless and unemployed become desperate, they may use desperate means to redress the imbalance" (2003:3, cited in Ikejiaku 2012). From this it can be inferred that economic resources are at the heart of both the conflict's initiation and its resolution.

Mustafa (2013) finds that Pakistan is exposed to multifaceted problems that lead it into conflict; however, the most important are socioeconomic. Despite the significance of these socioeconomic factors, they have remained unaddressed since Pakistan became an independent nation. Conflict in Pakistan is complex and multifaceted. Most of the problems are internal in nature, related to the drive to attain economic and social power. Political and economic solutions should be devised to sustainably resolve conflicts in the country.

In addition, Goodhand (2001) examined the effect of chronic poverty on grievances that lead to violence. Goodhand discovered that chronic poverty per se does not lead to the eruption of violence. However, if chronically poor people are denied a say in political affairs, the likelihood of conflict increases. Moreover, inequalities in societies of the same level (horizontal), exclusions from opportunities coupled with locational or identity territories may increase the tendency of the society to violence: political entrepreneurs become active in exploiting the discontent and grievances of society. A community that suffers from chronic poverty can be utilised as an important weapon to wage and sustain war. Poverty-stricken people may consider involvement in violence and predation as their sole option to sustain a livelihood. 
Tadjoeddin and Murshed (2007) found that economic deterioration and a rise in poverty are directly associated with the degree of conflict. They state that enhancement of economic growth and poverty alleviation are panaceas that will bring about social cohesion and unity.

Bohlken and Sergenti (2010) made a study of the causal relations between economic growth and ethnic violence in India which revealed that there is an inverse relationship between the two. The likelihood of conflict is inhibited by a boost in India's economy. Their study suggests that an improvement in economic progress serves as a tool that is part of the conflict resolution process and peace-building activities.

Kim and Conceição (2010) investigated the relationship between economic factors and the outbreak of conflict. The empirical results indicate that they are interlinked. Though the eruption of conflict can be attributed to several factors, lower levels of human development raise the likelihood of conflict. Furthermore, the violence further reduces economic values, leading to impoverishment by destroying existing wealth. The relationship between conflict and human development is like a vicious circle: the two reinforce each other. It is suggested that the formulation and implementation of policies that strengthen and sustain human development will have an indirect influence on reducing the likelihood of conflict.

Ikejiaku (2012) reveals that the cause-and-effect relationship between conflict and poverty is not unidirectional. Each affects the other, though the effect of conflict on poverty is more critical than the other way round. While the impact of conflict on poverty is direct, the latter's effect on conflict is indirect. Furthermore, no evidence exists that supports the hypothesis that conflict cannot result because of poverty.

The argument of other scholars is somewhat different to either of the stances that conflict leads to poverty or the reverse. Nelson (1998) argues that the association between conflict and economic grievance is indefinable, owing to the significant influence of non-economic factors. However, studies done recently reveal that the outbreak of conflict and its recurrence are explained significantly by economic situations (Kim 2010).

Atwood (2003) states that there is a strong association between deprivation of material necessities and the likelihood of violence. This could range from crimes that are committed in poverty-stricken areas resulting in social conflict to centre-city of the neighbourhood political instabilities.

There are several theories supporting the hypothesis that poverty and inequality lead to violence or conflict. Some of these include: “... frustration-aggression theory, the entitlement perspective, Marxian perspective, relative deprivation theory, liberal economic and democratisation theory, and human basic needs perspective" (Ikejiaku 2012:130).

According to relative deprivation theory, conflicts and violence erupt due to the disparity between one's stated right to entitlements and the actual reward (Gurr 1970). A study by Kimenyi and Ndung'u (2002) discloses that the conflict between Kikuyus in Kenya was mainly related to poverty and inequality before and after independence. Similarly, in Senegal poverty and inequality were the principal causes of conflict at Casamance (Humphreys \& Mohamed 2003).

Drez and Sen (1995, cited in Ikejiaku 2012) argue that apart from the direct correlation between impoverishment, inequality and wellbeing, a higher level of economic asymmetry inhibits society's drive to boost its valued capabilities. Inequality can be the driving force for tension and violence in a community. 
Darman (2003) adds that such disparities result from governance's failure to appropriately allocate resources, with some parts of the society being privileged and others disadvantaged. The burden of poverty due to mismanagement leads to frustration and anger, which give rise to violence.

Starr (2006) criticises the neo-liberal conception that overemphasises boosting the individual's incentives and undermines the role of socioeconomic injustice in causing violence. Starr criticises the assertions of neo-liberalism that socioeconomic injustice does not have a role in violent conflicts. He argues that in societal problems, socioeconomic aspects should be given due attention in order to effectively and sustainably solve them.

The third proposition that Goodhand (2001) briefly investigated is the causal relationship between greed, grievance and conflict. The study reveals that rebel groups have used grievances as a camouflage while they assert their financial interests in high-value items like diamonds and other primary products that can bring them money. To realise their financial interests, the rebel group generates grievances as a strategy, which leads the community to make them a hot issue. Hence, greed leads to conflict using grievance as an instrument.

The other school of thought argues that conflict results in poverty. Scholars who disagree contend that conflict is a driver towards poverty. Goodhand (2001:4) states that "Chronic poverty by itself is unlikely to lead to conflict - the chronically poor often lack political voice and organisation". In fact, the adverse impact of conflict on any country's economy and poverty is virtually an agreed-upon and accepted idea.

One of the three propositions Goldin (2001) has examined deals with the causal relations between conflict and chronic poverty. It was found that livelihood and entitlements are directly and disastrously affected by the eruption of conflict that intentionally destroys livelihoods, leading to chronic insecurity. The state of chronic insecurity further worsens chronic poverty. In fact, the magnitude of the impact varies according to age, gender, ethnicity and region. In the vast literature that discusses the cause-and-effect relationship between conflict and poverty, no conclusive assertion and consensus have yet been reached.

Sen (2008) argues that the factors thought to cause violence or conflict within and between communities should be seen in a systemic way. Economic conditions, social inequality, deprivation and other factors should be examined as integrated with each other and other pertinent factors to determine the root cause of conflict. One factor should not be singled out as important at the expense of others. An attempt to address an issue in isolation would inhibit one's understanding of the whole picture of the causes of violence.

Idemudia and Ite's (2006) finding is consistent with the assertions of Sen (2008). They state that to resolve the more than decades-old conflict in the Niger Delta region of Nigeria, an integrated approach should be adopted in dealing with the factors responsible for the occurrence of conflict in the region. The basic factors specified as causes for the conflict are economic, social and environmental, among others. A comprehensive solution that integrates the specified factors should be designed and implemented, one that sustainably resolves conflict and enhances ongoing development.

Murray (2001) notes that the methods adopted to resolve conflicts in Africa have achieved little success. One of the reasons is that the issue of the link between the violation of human rights and conflict is overlooked. As a general principle, the literature suggests that Africa needs to take a holistic perspective to solve its conflicts. As it becomes more complex to 
investigate all the causes of conflict in Africa, it is suggested there would be a more productive outcome if it was approached from the wider human rights perspective.

Warnecke and Franke (2010) state that the successful transformation of conflict into peace requires appropriate measures across the whole band of sectoral and socioeconomic dimensions. They note that expenditure during the post-conflict reconstruction phase is more than conflict prevention. As the likelihood of post-conflict societies to relapse into conflict is higher, serious attention and special measures are needed to prevent further eruption. They cite Collier et al (2003) that post-conflict, under conditions where the likelihood of relapsing into violent conflict is high, it is common practice to deploy military forces to the area to maintain security as the basis for peace-building endeavours. However, this could be perceived as militarisation of the peace process, which may hinder local ownership. It is suggested that active development engagement directed at preventing relapse into violence is a more effective approach. Development measures have the effect of reducing structural conflicts; They support civil society and enable local government to design non-violent dispute settlement strategies and structures. This leads to sustainable peace in the postconflict stage.

\section{Analysis of the socioeconomic causes of conflict in the San community of Platfontein}

\section{Factors responsible for conflict in the San community}

The lives of the !Xun and Khwe have been full of hardship. They lived in tents exposed to the extreme heat and cold of the Northern Cape while waiting for permanent settlement. These hardships were worsened by unemployment, poverty, social problems resulting from displacement and war experiences. These complications also triggered intra-community tension that eroded its cohesion and led to a break between !Xun and Khwe; moreover, they have contributed to alcohol addiction, violence and the rise in high school dropout rates. Some of the reasons for the lack of motivation to search for jobs and break the dependence syndrome are stated by Robins (2001:22) as:

... The paternalistic SADF military culture has produced a pervasive passivity and lack of initiative that could become a long-term obstacle to community self-reliance. Almost 10 years of waiting to move from this temporary relief camp to a formal settlement have demoralised many people and driven some to deep dependency, pessimism and alcohol abuse. Traumatic experiences of war and violence have predisposed the community to inward aggression and self-destructiveness, manifested in, for example, very high levels of alcohol abuse, domestic violence and rape.

The adult males and females are more dependent on the income of veterans in the community than is the case in other black communities of South Africa. This is evidenced by the fact that 51 per cent of residents at Schmidtsdrift are male. This contrasts with the case of other South African communities, where males are usually absent as they migrate to look for employment (Robins 2001). This implies that the adult males' motivation to gain an income and boost the family finances by searching for employment is quite limited. The poverty of the community can be tackled if the attitude of the youth is changed from the current inactive and unproductive one of relying on parents' income to a vibrant and productive one of selfgenerating an income. 
Generally, females account for a significant section of the communities. Ignoring this segment of a community in economic activities may have adverse effects on the livelihood of most families. With regards to the San community in Platfontein, females at Schmidtsdrift constitute 49 per cent of the population. However, formal employment of these members of the community in economic activities that enable them to generate income for a household is virtually non-existent. This situation further widens the gender disparity in the community (Robins 2001).

The cultural background has contributed to the Platfontein San community's lack of commitment to its own growth and development. Robins (2001) shows that their military background has influenced them to be less independent. In addition, they tend to admit and accept a paternalistic and hierarchical style of leadership, which runs contrary to entrepreneurial endeavours. Besides, the military culture is biased towards males, who reinforce the inhibition of females' involvement in economic undertakings.

Some of the factors that restrict the involvement of the San in socioeconomic activities include dysfunctional organisational and leadership dynamics. Shiwarra (n.d.a) explains that they do not have good leadership that works closely with the community. If this were so most of the problems they currently face could have been resolved. Lower educational qualifications and skills resulting from a lack of formal education are cited as bottlenecks in the San community. This situation restricted people from competing in a job market that demands specialisation (Robins, 2001). The lack of skills in the San community is witnessed by Sibongo (2014b), who confirmed that people do apply for jobs but are rejected due to lack of computer skills and the inability to speak English. Instead of completing their school studies, some of the youngsters spend their time drinking alcohol and smoking dagga, even at a young age.

The factors that drained the San community and led to economic impoverishment are its background and experiences in colonial times, being without land for quite long periods, and the policies of apartheid (Robins 2001). From this one can infer that these situations did not lay a foundation for a secure life for the San community. Without guidance, the working-age group of youth are vulnerable to addictions. This tends to stimulate the youth to commit unlawful acts that lead to conflict. As mentioned by Shiwarra (n.d.a), "Most of our young people abuse alcohol and that is why there is too much fighting and conflict. The young people do not respect their parents anymore."

The deep division between intra-San communities has become a barrier to communal economic development. This problem has been worsened by the delay in the provision of infrastructure and employment opportunities. These problems have become principal factors in the San communities' heightened frustration and conflict (Robins 2001).

Various efforts have been undertaken to empower the San community in Platfontein. This can be seen in the skills training that was organised in 2008 by the South African San Institute (SASI) to build the capacity of the community to participate in economic activities. More than 400 crafters from the three San communities participated in this skills-training workshop. In addition the institute attempts to have families from the San community manage small-scale farms such as vegetable gardens, chicken and goat kraals to encourage the community to engage in agricultural farming, which leads to self-sufficiency. The Institute's small-scale farming project has been scaled up to three cooperative groups. Five young people have been given tourist guide training; two people have been supported to become involved in a taxi business (SASI 2008). 
Sibongo (2014c) makes the point that both !Xun and Khwe prefer to be employed than to create their own jobs. They lack the self-confidence to establish and run their own business firms and feel very comfortable working in someone else's firm. From this one can infer that for the members of the San community to become more entrepreneurial, a change in their attitude towards running one's own business and building self-confidence through skillsoriented training is required.

Beyene (2014d) says that some initiatives are taken in the community to run small businesses. However, the whites administering the area do not allow the people to run small businesses, claiming that they are not legally authorised firms.

The lack of entrepreneurial skills is cited as a common problem in the San community. This is supported by the interviewee (Jack 2014a), who explains that business does not work well there. When a San person starts a business and gives items on loan, the customers do not repay on the due date. This causes the business to become bankrupt. However, the Indians running small businesses are doing well. Still another interviewee, (Jack 2014b), supports the fact that the San community is unable to do any business except selling alcohol. The main problem is that when one sells on credit, the repayment is poor and the business becomes bankrupt; then the Indians take it over.

The people have free land that can be used for irrigation but it is far from the water source (the river). With the use of technology the land could be irrigated, which demands capital capacity and skilled human resources. However, the San community in Platfontein does not have these resources; consequently, they rent the land to white farmers for grazing. In fact, the Khwe people have the capacity to become subsistence agriculturalists (Beyene 2014a).

In the past, because of the nomadic ways of the community, whatever a person had was shared among all communities, but nowadays everyone takes care of himself(Beyene 2014d).

It is said that because of the failed schooling system, many people are becoming dropouts. This leads them to spend their time in undesirable activities such as drinking tombo (a locally brewed beverage), taking drugs and becoming addicted. To meet these demands, some of the youth may get involved in stealing and similar activities. This situation results in conflict within the San community and with other communities affected by the unlawful acts (Beyene 2014b).

Beyene (2014d) explains that dropping out is partly attributed to the ignorance of parents. The parents do not have educational qualifications, but some of the children finish their schooling and some are dropouts. Their reason for discontinuing their school studies is that, as the parents themselves are not educated, they are unaware of the benefits of education. The parents' lack of awareness does not give them the motivation to influence their children to attend school. Secondly, the children are accustomed to drinking in the early morning and chatting; they prefer to spend the day drinking tombo to going to school.

\section{Economic factors as causes of conflict in the San community in Platfontein}

The !Xun people are the majority and the Khwe are the minority in Platfontein. The families of the San at Platfontein depend on the pension income of the grandparents who served in the SADF. The grandparents look after their grandchildren. Many people are dependent on a single person (the pensioner) in a family. Because of a shortage of resources, conflicts can happen between family members (Beyene 2014a). As the interviewee Swart highlights, economic factors are one of the causes of conflict in the community (Beyene 2014a). Swart 
adds that conflict is common between the Khwe and !Xun people of the San community. Mahongo (Beyene 2014b) also adds that the loss of the income earned by SADF soldiers was huge. Nowadays the increasing unemployment further lowers the income of the community.

Beyene (2014d) explains that currently, the San community depends on the pension income of retired military staff, monthly wages earned from farmers serving as security personnel and child grants of R250 per child until the child reaches 18 years old.

Sibongo (2014a) asserts that the main cause of the hardship and sufferings of the San community is the prevailing poverty. The situation is worsened by the fact that most of the youth who have completed their schooling are jobless. Moreover, the motivation of the matriculated youth to initiate and run their own businesses is low. This further exacerbates their economic deprivation and prolongs their unemployed status.

The study attempted to examine efforts to rehabilitate the San community after relocation. Studies indicate that some sort of attempt has been made, as Robins (2001) highlights. In Platfontein, a business plan was prepared with an emphasis on commercial agriculture that included ostrich-farming, olive production and cattle-ranching. However, these business plans were not implemented for various reasons, one of which is that the San in Schmidtsdrift were not interested in the envisioned economic activities. On the other hand, many of the San complain that they were not properly consulted when these business plans were prepared.

From this it can be inferred that had the rehabilitation programmes been effectively carried out, at least the economic challenge the community is facing might not be as severe as it is at present. Had the question of the economic livelihood of the communities been settled, at least the pace of the ongoing disparities between the !Xun and Khwe and the divisive tendencies and attitudes would have been slower. The economic disparity between the two groups in relation to income from the SANDF has widened the rift between them (Robins 2001).

Moreover, other factors that prevented the business plan from being implemented included the trap of the required overdraft of R850 000 the !Xun and Khwe Trust would be saddled with. In addition, the community were not willing to engage in any commercial agricultural activities before the promised housing and land materialised. Before settlement, the people became extremely doubtful and sceptical about engaging seriously in any planned economic activities (Robins 2001).

The study attempted to investigate the causes of economic problems in the community. Beyene (2014b) opines that no economic empowerment activities were undertaken in the community, an omission that led to poverty. The people are living in small houses along with their animals. The quality of the houses is very poor, the toilets are dry and the roads are not well prepared. Even though most of the community have the basic necessities of food, clothing and shelter, significant numbers of people do not. This implies that the poverty of the community is one of the reasons for the occurrence of conflict.

Beyene (2014b) supports the idea that the source of conflict within the community boils down to economic deprivation. Beyene (2014a) gives the example that currently people seeking jobs and higher positions are fighting among themselves. Furthermore, those who do not have an adequate income opt to spend the limited amount of money they get on locally brewed beverage called tombo. Spending lots of time drinking alcoholic beverages increases the likelihood of conflict, and it happens frequently in Platfontein. The high rate of 
unemployment in Platfontein also creates and aggravates social problems such as under-age pregnancies. This further worsens the economic burden, which in turn increases the possibilities for conflict within the community.

\section{Conflict between the two San communities!Xun and Khwe}

\section{Sociocultural and political causes of conflict}

Robins (2001) argues that the basis of conflict between !Xu and Khwe is political, dating back to the divisive rule of apartheid. The apartheid-era SADF actively enhanced ethnicisation using the phenotypic and racial stereotypes for the two communities; this has widened spatial separation and raised communication barriers between them. The same stereotyping has been further practised and developed by the members of the community who seek division rather than harmony and unity. Jack (2014e) states that the two communities are settled in Platfontein in two separate places, though these are in close proximity.

The "divide and separate" strategy adopted by the SADF has worked to some extent. This is supported by Dankane's (2014a) view that "we have different background and we come from different places. The problem of the past still exists. The people didn't like one another and the adults fought about positions." Moreover, Beyene (2014b) suggests that the two communities differ in various ways and should be separated to avoid conflict.

The validity of the divisive intention of the previous apartheid regime that considered the two tribes to be different is challenged by the youngsters from both!Xun and Khwe groups, who claim that they co-exist. This is supported by Robins (2001), who states that, because of the social distance between the !Xun and Khwe that has widened over time. With regard to a solution to the recurring conflicts between the two tribes, parents and the youth are not in agreement. The youth advocate socialisation as a potent force for unification between the two tribes. Unification helps to harmonise attitudes, which is important in resolving the recurring conflicts sustainably. On the other hand, the senior members of the San community in Platfontein consider that spatial separation serves as a barrier against conflict, as it reduces interaction between the two communities. They believe that tensions and conflicts can be sustainably reduced if the two tribes are separated. The youth see unification as the best solution because they attend the same school and have friends and lovers from both the !Xun and Khwe communities. This inter-tribe friendship serves as an important force of cohesion that strengthens the spirit of unification. However, the conflicting ideas for solutions between the youth and parents remain a challenge in the San community.

As far as the motivation and desire to obtain jobs is concerned, in relative terms, the Khwe people are highly motivated to work but the motivation of !Xun people is low. For this reason, most of those employed by white farmers as security guards are Khwe. Their monthly salaries enable the employed ones to support their families. This is one of the factors that give some of the Khwe people relative economic superiority over the !Xun people: in other words, the !Xun are economically inferior to the Khwe (Beyene 2014a).

It is said that language serves as a divisive as well as a unifying factor. According to Robins (2001), statistics show that while 15 per cent of Khwe people can speak the !Xun language in addition to their own, no !Xun people can speak the Khwe's language. In this case learning one another's languages may not be accepted by both of the communities and may even 
widen the division between them. However, the new generation's first language is Afrikaans for both !Xun and Khwe; this could serve as a unifying common language for both communities.

In relative terms, more Khwe people are employed than !Xun. Using the example of the radio station that transmits its programmes in both Afrikaans and local languages, initially the employment policy specified an equal number of workers from each clan. Accordingly, 50 per cent of the labour force was !Xun and the rest was Khwe. However, because of capacity problems and lack of work motivation, a significant number of !Xun employees have abandoned their jobs. Currently, about 70 per cent of the employees of the radio station are Khwe (Beyene 2014a). The ongoing widening social distance coupled with competition for jobs and housing could escalate tensions and division between the !Xun and Khwe communities (Robins 2001).

There are micro-finance non-governmental institutions that aim to support the poor. However, in the !Xun community there is a lack of skill to manage the loans they may take from the lending institutions. They also display inadequate financial management: there is a tendency to extravagance whenever people from the community obtain some income, in the form of festivities, much eating and drinking and visits to extended families. They do not have the habit of saving what they earn for the future (Beyene 2014a).

In the case of Khwe, unlike !Xun they have a culture of saving and it is common for a Khwe person to have a savings account. In addition, the Khwe people are inquisitive and search for more information about business and other issues and are therefore better informed. They prepare business plans and are very active in making money: for instance, they are involved in poultry farming and other business initiatives (Beyene 2014a).

Socio-cultural factors also have a significant influence on the eruption of conflict in the San community. This can be seen in the interview with Swart (Beyene 2014a; 2014c), who affirmed that conflicts that usually happen between the Khwe and !Xun people are mainly the result of cultural differences. Culturally and attitudinally the two clans are not the same. The Khwe clan intermingles relatively more than the !Xun with other communities around Platfontein, such as the black communities. The languages of the two groups are dissimilar: the !Xun language has more gestures than Khwe. There is language diffusion between the Khwe and black languages. Relatively, the !Xun's language is still in an original form. The Khwe people are more enquiring and are more motivated to seek information than the !Xun people, whose motivation to grow and prosper is lower and whose dependence mentality is higher. The two peoples of the San community have different points of origin: the Khwe come from Botswana and the !Xun are mainly from Angola. The !Xun are distinct from Khwe in various dimensions: customs, culture, language, literacy level, ambition (for advancement and growth), self-confidence and emotional health. These differences between the two communities increase the likelihood of conflict whenever misunderstandings happen between them (Beyene 2014b).

Moreover, the sociocultural disparities when combined with educational disparities may increase the possibility of misunderstandings, raising conflict between the two tribes. Within the two communities some sort of difference in educational status can be observed, as Swart (Beyene 2014a; 2014c) states.

Relatively, the Khwe are better at reading and writing and have greater potential for progress and advancement than the !Xun (Beyene 2014b). The overwhelming majority of !Xun people 
do not read or write. In terms of attrition or dropout rate at school, the Khwe people's performance is better as their number of dropouts is negligible. However, in the case of the !Xun people school performance is low and the dropout rate is very high.

Furthermore, it is indicated that the political leadership in the San community is one factor intensifying conflict within the San community. This is shown in an interview (Shiwarra 2014a) that revealed that people are fighting for leadership. In addition, the people who belong to different villages want to have leaders who assume power, which results in fights for leadership (Shiwarra 2014b). Similarly, Shiwarra (2014c) posits that the people are unable to work together due to the competition and hostile relationships among the leaders. It is the wish of the people to see the leaders work in peace and harmony to lead the community righteously. It is also asserted that the San people of Platfontein do not have high regard for the leaders, as the communities do not believe that they are just and trustworthy. The leaders are blamed for giving priority to their families' interests whenever there are job opportunities (Sibongo 2014g).

\section{Economic causes of conflict between San communities}

Economic disparities usually lead to an increase in the likelihood of conflict between communities (see Bohlken \& Sergenti 2010; Kim \& Conceição 2010; Starr 2006). This is the case between the majority !Xun and minority Khwe. As Robins (2001) indicates, the proportion of Khwe people employed as soldiers in the SANDF was 39 per cent, compared to 20 per cent in the case of !Xun. Moreover, a relatively higher proportion of Khwe than !Xun have attained higher positions in the military. Such a job imbalance increases the likelihood of rising tensions that could lead to conflict (Kimenyi \& Ndungu 2002).

When we examine the comparative economic status of the two communities, Swart (Beyene 2014a; 2014c) says that basically, Khwe are more involved in selling tombo. The !Xun people do not have the habit of brewing alcoholic beverages, although both groups drink tombo. Khwe people are involved in economic activities, while the !Xu are not. The Khwe people have some entrepreneurial skills that help them run small businesses (Beyene 2014a; 2014b). The relative economic disparities between these two communities could trigger conflict, which is consistent with the school of thought supporting the hypothesis that poverty and inequality lead to violence or conflict (Ikejiaku 2012:130). Drez and Sen (1995, cited in Ikejiaku, 2012) and others argue that inequality or economic asymmetry can be the driving force of tension and violence in a community.

The economic disparities between!Xun and Khwe can be seen in the type of assets they own and their motivation for engaging in small business activities. It is obvious that in most cases, the Khwe families own more assets than the !Xun. For example, the majority of Khwe people have satellite TV dishes. Khwe houses are better maintained than !Xun houses, which are mainly grass-roofed. Khwe people are involved in small business such as retail and taxi businesses (Beyene 2014a). In fact there are many small businesses run by Khwe people, such as the many Khwe taxi entrepreneurs (Beyene 2014a). Overall, according the interview report by Beyene (2014a), if the income earned by each community is evaluated separately, the Khwe people's per capita income is higher than that of the !Xun. This could become a cause for conflict, as the community that suffers most from the prevailing poverty can use any weapon it thinks will assert its interests (Goodhand 2001). 


\section{Conflict between the San and other communities}

The problem of hunger and joblessness has caused the San community to fight with other communities, stated in the interview as:

The main problem is poverty. This causes the children to leave their education. They fetch woods by cutting the fences of the farmers and we get into trouble with farmers. It is the poverty that lets us get in to conflict with communities (farmers). Now the children are turning back into the San community and started taking window glasses and selling it out (Jack 2014a).

That economic factors are causes of conflict is further supported by another interviewee, who noted that there was conflict in Angola when the San community worked with blacks. The causes were basically economic: the low wages for labour were unfair (Dankane 2014c; 2014d).

\section{Socioeconomic factors in the process of conflict resolution in the San community of Platfontein}

\section{Socio-cultural factors}

Sociocultural factors have a significant place in the process of conflict resolution in the San community. A witness from the San community (Mahongo 2013a; Sibongo 2013a) states that in the past a ceremony carried out at night was very important. By slaughtering a goat, the ceremony celebrated building the relationship and forgetting what has happened between the two parties who were in conflict. However, currently those at the ceremony eat and drink large amounts and then go back home. The next day they merely have a small meeting, greet each other and bid one another farewell.

If someone has emotional problems because of the conflict, the community is assisted by traditional emotional healers. According to witnesses (Sibongo 2013a; Sibongo 2014d; Jack 2014f) people with emotional problems visit the healer's house. The healer should be told all the facts of the case. Then the healer tells the person what to do and sometimes prescribes something to take or to use (Dankane 2014e).

Apart from economic compensation, in the past emotional healing was commonly carried out by consulting a traditional healer. The healer poses questions and the person who needs treatment must answer frankly. After analysing the situation the healer prescribes what actions the person must take (Dankane 2014f).

Jack (2014c) also adds that when the traditional leader comes to heal the person in trauma, the elders are supposed to gather and sing trance songs. The healer is believed to go into the trance and talk to the ancestors, which helps him receive the power to heal.

Even to proceed with the healing process requires a pledge of material things to the traditional healer. According to Jack (2014d), he is paid on an hourly basis. The payment is not given directly to the healer. It is placed in a bucket, in the belief that the ancestors will give the healer power to heal the people in trauma. If payment is not effected in the traditional way, the healing is less effective. 
The actual conflict resolution process is embedded in both economic and sociocultural elements enmeshed. This form of conflict resolution seems consistent with the ideas of Sen (2008) that the resolution process should not focus on economic factors and neglect social and other factors. Conflict resolution should be addressed under the premise of a holistic perspective.

\section{Economic factors}

Economic factors as incentives are used in the San community's traditional conflict resolution process, which includes economic compensation to the victim. The economic compensation partly explains the assurance of the completion of successful resolution of the conflict. A witness from the community states:

After violence, compensation should be given to someone and the nature of compensation
after violence is very different. It has its own procedure and only parents and leaders are
supposed to decide the amount of the compensation. Even in the past times, it was a
practice of the wrongdoer used to pay something valuable thing to the victim. During
this time pots or blankets were handed over to the victim as these items were important
valuables then. Currently, money can be used as a means of payment whereby the
amount to be paid is decided by the leaders of the community. In addition, in the past
ceremony was very important that has been done to bring the two parties to peace. They
set two three fires separately for kids, men and women while celebrating. Finally, they
call the two fighting persons and let them shake their hands. Then they break grass in
the middle and put it on each other's hair and drink water from the same cup indicating
the problem is resolved (Dankane 2014f; Sibongo 2014e). Sometimes a goat is
slaughtered in the victim's house (Sibongo 2014f).

Shiwarra (n.d.b) confirms that valuable items such as cows, money and goats are pledged by the family to the victim as compensation for the wrongful act.

In an interview conducted by Dankane (2014g), the respondent asserted that compensation was very important after violence. But before compensation is paid, both parents and leaders should come together and decide what to do.

This idea is strengthened by the respondent in another interview conducted by Dankane (2014h). In the past the leader and the parents discussed the case and decided on the type and amount of compensation, which could be a blanket or a pot. Currently, compensation can be paid in money and having the parties shake hands.

The actual conflict resolution process enmeshes both economic and sociocultural elements. This form of conflict resolution seems consistent with the ideas of Sen (2008) that the resolution process should not focus on economic factors and neglect social and other factors. Conflict resolution should be addressed from a holistic perspective.

Furthermore, even to proceed with the healing process it requires the pledge of material things to the traditional healer. According to Jack (2014d) on hourly basis the traditional healer is paid. The form of payment is not direct to the healer. It is put inside a bucket with the belief that the ancestors will give the power the healer to heal the people in trauma. If payment is not effected as per the traditional norm, the healer's service of healing reduces. 


\section{Recommendations suggested by the interviewees and the literature}

The community has the potential to utilise the land resources they have to their economic advantage. Robins (2001) states that the farmland owned by the San community is 13000 ha, which in addition is endowed with natural resources such as gypsum and diamonds. The community earns R12 000 per month by leasing out a little over half of the total farmland (7 000ha). Using the land for commercial agriculture and mining the minerals within it would have a significant impact on improving the economic wellbeing of the San community. This would in turn help to prevent conflict that derives from economic factors.

To give the San community a sustainable livelihood, the first thing to do is develop an adequately diversified socioeconomic environment. Their people's material deprivation should be addressed immediately. It is unlikely that the culture and language of the San community can be preserved and sustained through projects without establishing the socioeconomic security that is the community's top priority (Robins 2001).

Beyene (2014b) opines that economic empowerment of the community is the main factor that can alleviate the multifaceted problems and conflict within the community, between the two tribes and with other communities in Platfontein. In addition, training in skills that equip people to become entrepreneurs and run small businesses will help the people become self-reliant. Because of their background, people are not motivated to set up small businesses: training and orientation programmes that change their attitude to work and business are needed. Establishing centres and other infrastructures in the area that can employ people will also mitigate the current poverty. All the leaders should be dedicated to serving the society with impartiality.

Sen (2008) partly supports that idea that poverty is the main factor in conflict. He argues:

The influence of poverty and inequality has to be understood not through an exclusive concentration on deprivation and destitution in isolation from society and culture, but through looking for a larger and much more extensive framework with interactive roles of poverty and other features of society. The linking of poverty and injustice to violence does indeed have some plausibility, but there is neither any immediacy nor any inevitability there (Sen 2008:12).

When Sen's idea is applied to the situation of the San community in Platfontein, it has some validity. Beyene (2014b) opines that for the San community to sustain peace it should have enough land and a respected language of its own. This implies that economic resources should be treated in conjunction with other sociocultural elements in conflict resolution and peace-building activities.

Beyene (2014d) believes that the community should be encouraged to run small businesses. Alcoholic drinks should not be sold to people younger than 18. A uniform curriculum that includes subjects such as mathematics, statistics and biology should be designed and taught to the community.

It has been suggested that only government can solve the serious socioeconomic problems of the community. However, community leaders and the government should come together and take measures to resolve the problems, and the council must also become involved (Dankane 2014b).

The comments of the interviewees given above strongly support the school of thought that argues that economic disparities, caused by various factors and explained in different forms, 
are the principal causes of conflict. This implies that redressing socioeconomic problems is important both before and after a conflict arises in the San community.

\section{Conclusion}

The root cause of the intra-community conflict among the San and with other communities is their historical displacement and dispossession of land. The new lifestyle, which depends on the income of a few veteran members of the community, is one factor in the conflict within the San community and between them and other communities.

The paternalistic employment culture has created a dependency that reduces motivation for self-reliance and independence. The people tend to accept a paternalistic and hierarchical style of leadership as opposed to one that encourages entrepreneurship. The extreme dependency of San youth on obtaining employment as opposed to engaging in entrepreneurial activity, accompanied by a lack of jobs, results in hopelessness, violence, alcohol addiction, high dropout rates and rape. Moreover, the SADF employment culture was biased towards males and ignored females' involvement in economic activities. Economic deficiencies are another cause of conflict within the San community and with other communities. This demands a concerted effort to change the attitude of the community and transform them from jobseekers to job creators.

Apart from the economic reasons, the parents' lack of appreciation of the importance of education (because they themselves are not educated) means they are not motivated to guide their children's education, which has contributed to rising dropout rates. These dropout students are exposed to alcohol addiction and become involved in activities that create conflict in the community.

Furthermore, lower educational qualifications; fewer skills due to lack of formal education; and poor command of English are cited as barriers for the San community, and make them less competitive in the job market. The capacity of the community to become competitive for jobs and creators of jobs must be upgraded.

That the current leadership is not working closer with the San community in Platfontein is one reason for the erosion of harmony and unity within the community, and increases the likelihood of conflict erupting within the community. Concerned parties need to give this matter due consideration.

The efforts undertaken to empower the San community are very limited and must be carried out at a higher level to lift the community out of the prevailing poverty. The delay in the provision of infrastructure and employment has aggravated this poverty, which can be mitigated by concerted effort and support to make the land produce a variety of marketrelated products.

The conflict between the two tribes is attributed to the divisive political rule adopted during the apartheid regime in South Africa. This is practised by separating the two communities by an ethnicisation strategy that amplifies phenotypic and racial differences into stereotypes.

The economic asymmetries between !Xun and Khwe are causes of conflict. Although both tribes belong to the same San community, their attitude and motivation towards work is different. In relative terms, Khwe are more highly motivated to work and higher numbers are employed than !Xun. Khwe seek information more and are better motivated to run small 
businesses than !Xun. In relative terms and on average, the Khwe own more assets than the !Xun. The economic disparity between the two tribes is one factor that triggers conflict. Another is the widening of social distance along with competition for jobs and housing, which increases the tensions and divisions between the two communities. In addition, the Khwe have a culture of saving, while spontaneous festivity and extravagance are common among the !Xun.

The sociocultural disparities combined with educational disparities increase the possibility of misunderstandings between the two tribes that can develop into conflict.

Conflict between the San community and other white communities is caused by hunger and joblessness. The conflict that used to happen between the San community and other black people was economic in nature: the San's economic reward for their labour was unfairly small.

Sociocultural factors have a prominent place in conflict resolution in the San community. A traditional ceremony is used to repair the relationship and let the conflicting parties forget what has happened between them. Apart from the ceremony, compensation as decided by the elders is given to the victim's family as one way of resolving conflict. In addition, those with emotional problems are healed through the services of a traditional healer, who must receive economic reward. In summary, economic factors serve as both causes and remedies for conflict in the San community of Platfontein.

\section{Recommendations}

The economic deficiency and disparities are revealed as principal causes for conflict among the San and with other communities. This demands concerted effort by concerned bodies to empower the community economically through the provision of opportunities for employment. Moreover, training based on lived experiences should be provided to change the attitude of the community members and transform them from being job seekers to job creators (entrepreneurs). Furthermore, training on ethical values that strengthen the San communities' traditional norms, and the importance of education (schooling), should be provided to the community members.

Endeavours that upgrade the capacity and communication skills of the members of the community be carried out to empower community members to compete for jobs in the market.

The leadership of the Platfontein communities should work closely with the community, give due attention to their concerns and solve their problems and conflict in consultation with the community.

To mitigate the prevailing poverty (cause of conflict) of the San community in Platfontein, support should be provided to the San community to encourage them directly to use their lands and produce a variety of market-related products to sell.

\section{References}

Atwood, B. 2003. The link between poverty and violent conflict. New England Journal of Public Policy 19(1):158-165. 
Bohlken, AT \& Sergenti, EJ. 2010. Economic growth and ethnic violence: An empirical investigation of Hindu-Muslim riots in India. Journal of Peace Research 47(5): 589600.

Brinkman, H-J. 2001. Preventing civil strife: an important role for economic policy. DESA Discussion Paper No. 20: 1-27. Accessed on 04 September 2014 from http://www.un.org/esa/esa01dp20.pdf

Centre for the Study of Violence and Reconciliation (CSVR). 2009. Why does South Africa have such high rates of violent crime? Accessed on 04 September 2014 from http://www.csvr.org.za/docs/study/7.unique_about_SA.pdf

Collier, P. 2006. Economic causes of civil conflict and their implications for policy. Department of Economics. Oxford University, pp. 1-26. Accessed on 09 July 2014 from http://users.ox.ac.uk/ econpco/research/pdfs/EconomicCausesofCivilConflictImplicationsforPolicy.pdf

Collier, P, Lane Elliot, V, Hegre, H, Hoeffler, A, Reynal-Querol, M \& Sambanis, N. 2003. Breaking the conflict trap: civil war and development policy. Washington DC: The World Bank.

Dramen, R. 2003. Poverty and conflict in Africa: explaining a complex relationship. AfricaCanada Parliamentary Strengthening Programme, Addis Ababa. Accessed on 03 September 2014 from http://www.harep.org/ifaapr/semi.pdf

Dreze, J\& Sen, A. 1995. India: economic development and social opportunity. Bombay, Calcutta, Madras, Delhi: Oxford University Press.

Goodhand, J. 2001. Violent conflict, poverty and chronic poverty. INTRAC, Working Paper 6, Chronic Poverty Research Centre (CPRC). Accessed on 09 July 2014 from http://www.chronicpoverty.org/uploads/publication_files/WP06_Goodhand.pdf

Gurr, T. 1970. Why men rebel. Princeton: Princeton University Press.

Humphreys, M \& Habayeag, M. 2003. Senegal and Mali. Paper Prepared for Case Study Project on Civil War: New Haven, CT. Accessed on 03 September 2014 from http://www.columbia.edu/ mh2245/papers1/sen_mali.pdf

Idemudia, U \& Ite, UE. 2006. Demystifying the Niger Delta conflict: towards an integrated explanation, mainstreaming the African environment in development. Review of African Political Economy 33(109):391-406.

Ikejiaku, B-V. 2012. Poverty-conflict nexus: the contentious issue revisited. European Journal of Sustainable Development 1(2):127-150.

Irobi, E. 2005. Ethnic conflict management in Africa. A comparative case study of Nigeria and South Africa. Conflict Research Consortium, Colorado: University of Colorado. $\begin{array}{lllll}\text { Accessed on } & 03 & \text { September } & 2014\end{array}$ http://www.beyondintractability.org/casestudy/irobi-ethnic

Kim, N \& Conceição, P. 2010. The economic crisis, violent conflict, and human development. International Journal of Peace Studies 15(1):29-43.

Kimeny, M \& Njugana, N. 2002. Sporadic ethnic violence: why has Kenya not experienced fullblown civil war? Prepared for Case Study Project on Civil War: New Haven, CT. $\begin{array}{lllll}\text { Accessed } & \text { on } & 03 & \text { September } & 2014\end{array}$ 
https://web2.uconn.edu/ciom/Kimenyi/Papers/kimenyi\%20ptr\%20ethnic\%20violence. pdf

Krueger, A \& Maleckova, J. 2003. Education, poverty and terrorism: is there a causal connection? Journal of Economic Perspectives 17(4):119-144.

Luckham, R, Ahmed, I, Muggah, R \& White, S. 2001. Conflict and poverty in sub-Saharan Africa: an assessment of the issues and evidence. IDS Working Paper No. 128. Accessed on 04 September 2014 from https://www.ids.ac.uk/files/dmfile/Wp128.pdf

Murray, R. 2001. Preventing conflicts in Africa: the need for a wider perspective. Journal of African Law 45(1):13-24.

Mustafa, U. 2013. Determinants and implications of major conflicts in Pakistan. Millennial Asia 4(1):67-86.

Nelson, J. 1998. Poverty, inequality and conflict in developing countries. Rockefeller Brothers Fund Project on International Security.

Robins, S. 2001. South Africa, Part I, in Robins, S, Madzudzo, E \& Brenzinger, M, Regional assessment of the status of the San in Southern Africa: an assessment of the status of the San in South Africa, Angola, Zambia and Zimbabwe. Legal Assistance Centre (LAC), Namibia.

Sandole, D. \& Van der Merwe, H. (Eds). 1995. Conflict resolution, theory, and practice. New York: Manchester University Press.

Sen, A. 2008. Violence, identity and poverty. Journal of Peace Research 45 (1): 5-15.

South African San Institute (SASI). 2008. Annual report. Accessed on 14 July 2014 from http://www.sasi.org.za/img/Sasi\%202009\%20Annual\%20Reports.pdf

Starr, MA. 2006. Growth and conflict in the developing world: neo-liberal narratives and social-economy alternatives. Review of Social Economy 64(2):205-224.

Tadjoeddin, MZ \& Murshed, SM. 2007. Socio-economic determinants of everyday violence in Indonesia: an empirical investigation of Javanese districts, 1994-2003. Journal of Peace Research 44(6):689-709.

Warnecke, A \& Franke, VC. 2010. Sustainable conflict transformation: an analytical model for assessing the contribution of development activities to peace-building. International Journal of Peace Studies 15(1):71-93.

\section{Interviews}

Beyene, Hailay. 2014a. Interview with Hennie Swart Block: Faircity Hotel, Pretoria. 11 July 2014.

2014b. Interview with Mario Mahongo Block: Faircity Hotel, Pretoria. 11 July 2014.

2014c. Interview with Hennie Swart 2014c Block: Faircity Hotel, Pretoria. 12 July 2014.

2014d. Interview with Norman Jack 2014d Block: Faircity Hotel, Pretoria. 12 July 2014.

Dankane, Rassie. 2014a. Interview with Fani Mahongo Block: Villolusu, Platfontein. 21 May 2014. 
2014b. Interview with Lino Dala Block: Villolusu, Platfontein.

2014c. Interview with B. Luka Block: Villolusu, Platfontein. 05 February 2014.

2014d. Interview with P. Kongo Block: Villolusu, Platfontein. 11 February 2014.

2014e. Interview with Voster Litratu Block: Villolusu, Platfontein. 21 January 2014.

2014f. Interview with M. Fulai Block: Villolusu, Platfontein. 21 January 2014.

2014g. Interview with Maria Block: Villolusu, Platfontein. 21 January 2014.

2014h. Interview with Casro Block: Villolusu, Platfontein. January 2014.

Jack, Norman. 2014a. Interview with Arturi Batista. Block: 4, Platfontein. 21 Jan 2014.

2014b. Interview with Adriand Kasanga Block: 4, Platfontein. 21 Jan 2014.

2014c. Interview with Vridie Driben Block: Morosani, Platfontein. 22 May 2014.

2014d. Interview with John Mushamba Block: Morosani, Platfontein. 22 May 2014.

2014e. Interview with Mbumbo Katimo Block: Morosani, Platfontein. 22 June 2014.

2014 f. Interview with Shimuma Angola Block: 4, Platfontein. 24 March 2014.

Shiwarra, Karina. n.d.a. Interview with Rebekka Kaye. Block: Kamatoka, Platfontein.

n.d.b. Interview with Salone Ndane. Block: Kamatoka, Platfontein.

4014a. Interview with Kasongo Tsitawu. Block: Kamatoka, Platfontein. 21 Jan 2014. 2014b. Interview with Kapande Sangara. Block: Kamatoka, Platfontein. 21 Jan 2014. 2014c. Interview with Sasoria Mushamba. Block: Kamatoka, Platfontein. 21 Jan 2014.

Sibongo, Hanzi. 2014a. Interview with Gerber Jetembo Block: Morosani, Platfontein. 01 April 2014.

2014b. Interview with Oucho Ndumba Block: Morosani, Platfontein. 28 March 2014.

2014c. Focus group. Venue: Knowledge Centre, Platfontein. 29 May 2014.

2014d. Interview with Eriena Ditso Block: Morosani, Platfontein. 27 March 2014.

2014e. Interview with Max Katjara Block: Morosani, Platfontein. 28 March 2014.

2014f. Interview with Albertus Ndumba Block: Morosani, Platfontein. 28 March 2014.

2014g. Interview with Nagare Kapunda Block: Morosani, Platfontein. 24 March 2014.

2014 h. Interview with Kazungu Sibongo 2013a Block: Kamatoka, Platfontein. 11 December 2013.

Mahongo, Chakwanda. 2013a. Interview with Ghita Sabora Block: 001/05, Platfontein. 24 January 2013. 